\title{
Functional Ankle Instability Prevalence and Associated Risk Factors in Male Football Players
}

\author{
A. Cruz ${ }^{1,2,3 *}$, R. Oliveira4, A. G. Silva1,5 \\ ${ }^{1}$ School of Health Sciences, University of Aveiro, Campus Universitário de Santiago, Aveiro, Portugal \\ ${ }^{2}$ Laboratory of Neuromuscular Function, Faculdade de Motricidade Humana, Universidade de Lisboa, Lisboa, Portugal \\ ${ }^{3}$ Centro Hospitalar e Universitário de Coimbra, Coimbra, Portugal \\ ${ }^{4}$ Neuromuscular Research Lab, CIPER, Faculdade de Motricidade Humana, Universidade de Lisboa, Lisboa, Portugal \\ ${ }^{5}$ CINTESIS.UA, University of Aveiro, Campus Universitário de Santiago, Aveiro, Portugal \\ Email: *acruz@ua.pt
}

How to cite this paper: Cruz, A., Oliveira, R. and Silva, A.G. (2020) Functional Ankle Instability Prevalence and Associated Risk Factors in Male Football Players. Open Journal of Orthopedics, 10, 77-92. https://doi.org/10.4236/ojo.2020.104010

Received: February 14, 2020

Accepted: April 19, 2020

Published: April 22, 2020

Copyright (C) 2020 by author(s) and Scientific Research Publishing Inc. This work is licensed under the Creative Commons Attribution International License (CC BY 4.0).

http://creativecommons.org/licenses/by/4.0/

\section{Open Access}

\begin{abstract}
Background: The injuries sustained in football most frequently occur to the lower extremity, with ankle and knee being the most affected joint segments. Many studies have defined ankle sprain as one of the most common sports injuries with an annual incidence rate of $15 \%$ to $45 \%$, however, there's a lack of studies in football regional leagues. Risk factors like anthropometric measures, field position, dominant limb, previous injury have been described as being associated with ankle injuries in the elite sports context. The primary aim of this study was to determine prevalence rates of self-reported ankle instability in regional leagues. A secondary aim was to explore the presence of extrinsic factors affecting ankle instability in these football players. Methods: The heads of all clubs $(n=66)$ from Coimbra and Aveiro (Portugal) regional male senior football divisions during season 2016/2017 were contacted by e-mail or telephone to enter the study, and 58 gave their permission to include their athletes. Then, all players from each of these 58 teams were invited to enter the study $(n=1044)$ and a total of 589 athletes participated. Demographic and anthropometric data were recorded concerning age, height, weight, years of training, mean number of training hours, position in camp along with specific questions related to an ankle injury. All participants were asked about their previous history of injury, reinjury, feeling of giving-away and where also asked to fill the Cumberland Ankle Instability Tool. Results: A total of $290(49.2 \%)$ athletes reported a history of at least one previous sprain and, from these, 170 (58.6\%) repeated the injury and 112 (19\%) reported sensation of "giving-away". A significant association was found be-
\end{abstract}


tween injury, recurrence and subjective feeling of giving away $(\mathrm{p}<0.05)$. The player field's position was found to be associated with ankle instability, with defenders and forwards having higher rates of self-reported instability. No other significant associations were found. Conclusion: Along with intrinsic factors (age and injury repetition), some extrinsic factors were found to be associated with instability rates in professional regional football players (exposure time, and position on the field) suggesting the need for specific prevention strategies.

\section{Keywords}

Chronic Ankle Instability, Epidemiologic Study, Injury Prevention, Football

\section{Introduction}

Football is one of the most popular sports worldwide, with an increasing number of active players as well as spectators [1]. Assuming that one athlete plays on average 100 hours of football per year (about 50 hours per player for a local team, up to 500 hours per player for a professional team), it is estimated that every player will incur at least one performance-limiting injury per year [2]. In a 15-year epidemiological study, Agel et al. [3] found that approximately $17 \%$ of game and practice injuries restricted participation for at least 10 days post-injury.

The injuries sustained in football most frequently occur to the lower extremity, with ankle and knee areas being the most affected [3]-[7]. Studies have defined the ankle sprain as one of the most common sports injuries, with a value of $15 \%$ to $45 \%$ incidence over football season [3] [8]. Most ankle sprains are due to lateral or medial forces over the ankle or foot resulting in excessive inversion or eversion, respectively. Ankle sprains represent $75 \%$ of all ankle injuries and $85 \%$ to $90 \%$ occur in inversion [9] [10]. Functional treatment of an acute ankle inversion trauma leads to full recovery in the majority of the patients, but more than $40 \%$ of these patients suffer from recurrent sprains or giving way [11] [12].

Ankle joint instability includes both mechanical and functional instability conjoined with a wider range of possible dysfunctions. Mechanical instability refers to objective measurements of ligament laxity, whereas functional instability is a subjectively reported phenomenon characterized by repetitive episodes of "giving way" or instability about the ankle during daily living and sports activities and/or the incidence of recurrent, symptomatic ankle sprains [13] [14] [15] [16]. Along with increased laxity, patients with chronic ankle instability are thought to have disturbed neuromuscular control of the ankle caused by damage to muscles, receptors or nerves by the initial ankle inversion injury [13] [14]. Associated with ankle instability, there are impaired proprioception, neuromuscular and postural control, and strength deficits [11].

Also, individual personal factors, such as a history of musculoskeletal injury and level of self-efficacy, will affect perceptions and behaviors [17]. How a pa- 
tient responds to impairments, influences his or her perception of the injury and behavior, including motor output, in the presence and aftermath of the injury [17].

Despite the lack of consensus, some risk factors for foot and ankle injuries are listed in literature: anthropometric measures [18] [19], lack of structured warmup training or inadequate training [20] [21], previous injuries [20] [21], dominant limb [22] [23], and position in the field [22].

The prevalence and impact of ankle sprain on society and healthcare systems along with sports structures support the need for continued research related to the prevention, treatment, and rehabilitation of ankle sprains and their associated sequelae [9].

Most studies to date have focused on prevalence rates and risk factors in elite teams, but the continuous growth of smaller teams and the increasing number of participants justify the need for studies of this different context. While the level of competition is lower than national leagues, athletes from regional teams have poor environmental training conditions, less intense training or structured warm-up routines and are likely to do not have a specialized medical team in their club to support them in case of an injury when compared to elite teams. These factors can contribute to higher rates of chronic ankle instability. Therefore, the primary aim of this study was to determine prevalence rates of self-reported ankle instability in football players from professional senior regional divisions in two districts of Portugal's central area. A secondary aim was to explore the association between extrinsic factors and ankle instability in these football players.

\section{Methods}

\subsection{Participants}

All clubs $(n=66)$ from Coimbra and Aveiro regional male senior football divisions ( $\mathrm{n}=66$ ) during season $2016 / 17$ were contacted by e-mail or telephone requesting permission to include their athletes in the present study. A total of 58 clubs answered positively. Then, all players from each of these 58 teams were invited to enter the study. We included in the study all adult male players who gave their written consent and who were playing without any clinical restrictions. Participants were excluded if they reported: 1) systemic pathology from any source which affects balance, reflexes, muscle strength, neuro-motor control (e.g., multiple sclerosis, vestibular Pathology); 2) lower limb fractures in the 2 years preceding the study; 3 ) previous injuries of the knee or hip of the same lower limb or surgery to one of the ankles; 4 ) a sprain 3 months before the study and 5) current treatment for the ankle. These criteria were defined in line with the recommendation from the International Ankle Consortium [24].

A paper-based questionnaire made by the authors (Appendix) used to collect data on age, height, weight, years of training, mean number of training hours along with specific questions related to ankle injury. These include: previous history of injury, reinjury, and feeling of giving-away. Also, athletes that re- 
ported to: 1) have had at least one sprain, and functional inability to load while walking using crutches [25]-[29]; and to 2) have had at least a repeated sprain (recurrence) after the first injury or subjective feeling of instability or "giving away" on the ankle [25]-[29], were then asked to fill in the Cumberland Ankle Instability Tool [Portuguese version] [30]. A score of 24 or less on scale Cumberland Ankle Instability Tool [Portuguese version] was indicative of functional ankle instability in line with the International Ankle Consortium guidelines [7]. The Cumberland Ankle Instability Tool [CAIT] is a simple, reliable, and valid questionnaire for discriminating and measuring the severity of functional ankle instability enabling more homogenous subject groups to be identified, objectively defined, and compared [31].

\subsection{Statistical Analysis}

All statistical analyses were conducted using SPSS for Windows Version 15.0 (SPSS Inc., Chicago, IL, USA). A global analysis for sample profile was made using descriptive statistics and presented as means \pm standard deviations (SD) for continuous variables and as absolute frequencies for ordinal and nominal variables. Chi-squared statistical tests were carried out to assess if the occurrence of serious sprains, repeated sprains and instability varied among playing positions as well as dominant limbs. A t-student test was applied to assess for between group differences in terms of age, height, weight, or weekly training hours as well as CAIT values. Potential associations between variables such as history of injury, reinjury and giving away episodes were explored using the Spearman Rho test. Spearman Rho r-values $(r)$ were interpreted as weak (0.01 - 0.40), moderate $(0.41-0.69)$, or strong $(0.70-1.00)$ [32]. The significance value was established at $\mathrm{p}<0.05$.

\section{Results}

A total of 1044 athletes from 58 clubs were invited to participate in the present study. Of these, 589 (56.4\%) male football players accepted to participate: 68 goalkeepers, 197 defenders, 177 midfielders and 147 forwards and their mean ( \pm standard deviation) age, height and weight was $24 \pm 5$ years old, $177 \pm 6.3 \mathrm{~cm}$ and $77 \pm 8 \mathrm{Kg}$, respectively.

Of the 589 athletes, 290 (49.2\%) reported a history of previous sprain. Considering these groups of 290 athletes, 170 (58.6\%) reported having repeated the injury and $112(19 \%)$ reported subjective feelings of "giving-away".

A total of 117 (40\%) of the athletes that reported a history of injury, scored less than 24 in CAIT in, at least, one of the limbs, i.e., had self-perceived instability. From these 117 athletes, $48(41 \%)$ presented bilateral instability, with the remaining presenting instability in the right $(\mathrm{n}=42,36 \%)$ or left lower limb $(\mathrm{n}=$ $27,23 \%)$. Considering the total sample, it is important to notice that a proportion of 1 in every 5 players (19\%) presents instability and, from these, 2 in every 5 players (41\%) presented bilateral complaints. 
Our results show that the position in camp is associated with the occurrence of serious ankle sprains $(\mathrm{p}=0.009)$, as well as the presence of instability $(\mathrm{p}=$ 0.02 ) as presented in Table 1. In the analysis of cell count versus expected count, we found defenders and forwards to have greater rates of injury and instability.

Most of our athletes chose "right" as the dominant member, in a total of $82 \%$. Our study found no differences between rates in right or left-sided in the existence of injury, reinjury or the presence of instability (Table 1). However, considering giving away episodes, our study shows an association between the dominant limb and existence of giving-away episodes $\left(p=0.02, \chi^{2}=9.69\right)$ with a higher cell count in left dominance athletes, meaning left-sided players report higher rates of giving-away episodes.

Also concerning laterality and how it is related to the side of instability, a significant association was found ( $\left.\mathrm{p}=0.02, \chi^{2}=14.52\right)$, indicating that instability, as measured with CAIT, was associated with dominant limb (Table 1).

An important result of our study was defining the association between first injury and the recurrence as well as first injury and subjective feelings of giving-way

Table 1. Results concerning intrinsic and extrinsic factors related to ankle injury.

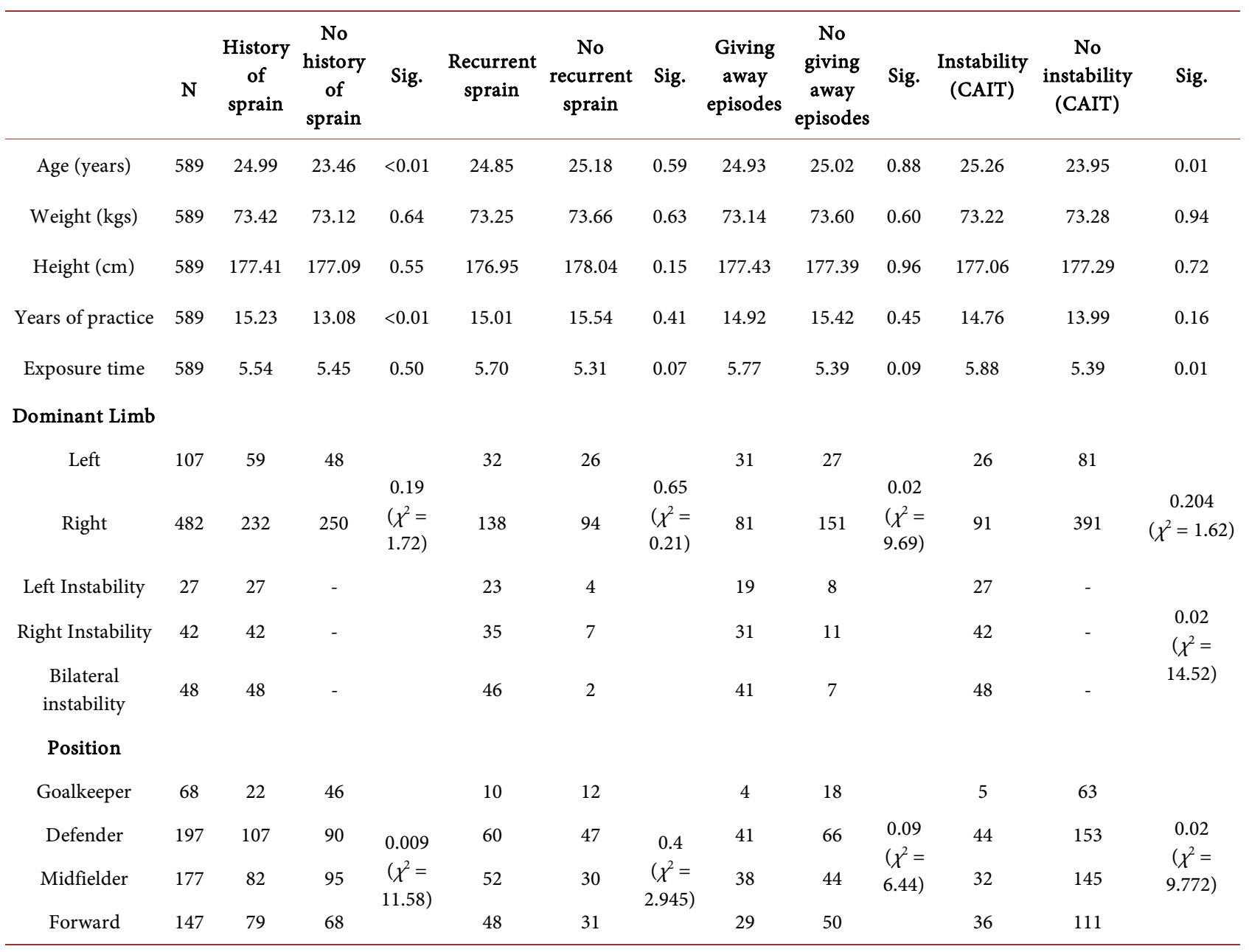

Sig. - Level of significance $\mathrm{p}<0.05$. 
and instability. We found a significant association between a first injury and a subsequent recurrence injury as well as with episodes of giving away and instability with Spearman Rho r-values (r) reflecting moderate $(0.41-0.69)$ correlations (Table 2).

Reinjury was also associated with giving-away with a moderate correlation and giving-away was strongly correlated with CAIT values (Table 2).

\section{Discussion}

Male football players in regional teams reported a high prevalence of ankle sprains, reaching half of the total number of athletes in our sample along with high rates of reinjury (58.6\%). The number of reinjuries observed and the tendency for these injuries to be chronic may suggest that rehabilitation programs used at clubs may not be adequate [22]. Equally relevant was the finding that half of the players with reinjury develop self-perceived ankle instability and subject to reflection. The fact that two in every five players with instability present a bilateral problem. Such values should lead to some reflexion from either technical teams or medical teams once they represent a significant loss of players' availability as well as associated expenses and. More importantly, leave sequelae and chronic impairments with effects on athlete's future sports performance and well-being.

Studies regarding injuries associated with different skill levels have produced contradictory results. Nielsen and Yde [33] found the injury rate during games was highest at the division level and lowest at the series level. Whereas during practice, the outcome was the reverse. Blaser and Aeschlimann reported that the highest frequency of injury was seen in the lower leagues [2]. The need for more studies targeting lower-level competition is evident to identify specific needs.

The context in competition level is usually related to different training equipment, different turf conditions along with fewer spending time for practice. Teams from lower competition levels have fewer training periods during a week. In a study with top Swedish male football teams, the average number of training

Table 2. Spearman correlation between injury, reinjury, giving-away and self-perceived instability.

\begin{tabular}{|c|c|c|c|c|c|c|}
\hline & & & $\begin{array}{l}\text { History } \\
\text { of sprain }\end{array}$ & $\begin{array}{l}\text { Recurrent } \\
\text { sprain }\end{array}$ & $\begin{array}{c}\text { Giving-away } \\
\text { episodes }\end{array}$ & $\begin{array}{c}\text { Instability } \\
\text { (CAIT) }\end{array}$ \\
\hline \multirow{4}{*}{ Spearman rô } & History of sprain & $\begin{array}{l}\text { Correlation } \\
\text { Coefficient }\end{array}$ & & $0.647^{\star \star}$ & $0.493^{\star *}$ & $0.504^{\star *}$ \\
\hline & Recurrent sprayn & $\begin{array}{l}\text { Correlation } \\
\text { Coefficient }\end{array}$ & $0.647^{\star *}$ & & $0.553^{\star *}$ & $0.657^{\star *}$ \\
\hline & $\begin{array}{c}\text { Giving-away } \\
\text { episodes }\end{array}$ & $\begin{array}{l}\text { Correlation } \\
\text { Coefficient }\end{array}$ & $0.493^{\star *}$ & $0.553^{\star *}$ & & $0.741^{\star *}$ \\
\hline & Instability (CAIT) & $\begin{array}{l}\text { Correlation } \\
\text { Coefficient }\end{array}$ & $0.504^{* *}$ & $0.657^{\star *}$ & $0.741^{\star *}$ & \\
\hline
\end{tabular}

${ }^{* *}$ The correlation is significant at level 0.01 ( 2 extremities). 
sessions/week recorded was 5.7 with an average weekly period of 7.5 to 10.5 hours. In our study, mean number of hours for exposure time during weekly training was 5.5, usually distributed in 3 training sessions. This difference is important and may be compelling of the need for more technical training leaving aside adequate warm-up or stretching periods when considering minor leagues as the ones we are studying.

Concerning risk factors, we found no association between anthropometric features and ankle injury, reinjury or instability. Hägglund et al. [34] found that none of the anthropometric variables [height. weight. BMI] were significantly associated with injury. Milgrom et al. [18] reported that during basic training. male military recruits who were taller and heavier were at increased risk of suffering an ankle injury [35]. Different sports with specific technical gestures and movements and different contexts disable the possibility of general conclusions. So further studies must be enrolled focusing on anthropometric measures to determine if it represents a risk factor to consider particularly in contact sports like football and associated with ankle injury.

Although most authors have stated that the field position played does not influence the injury rate [36] [23]. Other studies [37] [38] found that position played could determine a greater risk of injury. In a study concerning youth football, Price et al. (2004) found defender and midfielders sustained higher rates of injuries [37] while Hawkins and Fuller found the same risk associated with defenders. We found defenders and forwards to have higher rates of injury and instability. The high injury incidence among defenders could well be attributed to the need for defenders to take greater risks and be more reactive to prevent attacking situations developing and goals being scored [38] with higher intensity in contact as well as heading and jumping associated. Advanced players usually sprint and tackle before kicking and are also subjects of contact from other team defenders. Higher velocity in attacking positions requiring a constant change of direction and acceleration and deceleration may lead to higher injury probability.

These studies refer to overall injuries, not specifically to ankle injury or instability, pointing the need to develop specific analysis focusing on different types of injuries.

Although the evolution of football tends to make players more available to change field positions, the fact is that defenders maintain their defending tasks, despite different coaching strategies. While more advanced players also maintain offensive strategies related either with physical performance forcing contact and tackling or velocity. Defining the field position as an extrinsic risk factor would be important to develop different prevention strategies amongst players, creating specific training protocols.

The literature is not clear whereas limb dominance being a risk factor for suffering an ankle-ligament sprain or to develop signs of instability. Limb dominance has been implicated as a risk factor for lower extremity trauma because 
most athletes place a greater demand on their dominant limb producing increased frequency and magnitude of moments about the ankle particularly during high-demand activities that place the ankle at risk [28]. Our study focused the question in the relation between laterality and chronic ankle instability and found a statistically significant portion of athletes showed signs of self-perceived instability according to CAIT results in their dominant limbs. It remains undeniable that athletes tend to develop a great number of automatic patterns with a dominant limb preference (kicking. landing from jumps. initiate a sprint) placing them under higher stress and demand. Considering landing from jumps is one of the injury mechanisms [20], along with contact between players [2] [39] (which can occur during kicking) it is plausible that dominant limbs are subject to a higher risk of injury/reinjury. Also, we should expect athletes to be more aware of subjective feelings related to their limb of preference and even having greater memory of events associated with them. The laterality issue is, therefore, an aspect with which the athletes may present higher retrospective confidence. Also worthy of reflection is the high rate of bilateral instability which may lead to the need for a deeper analysis concerning the origin of the problem, once it may be related to central changes concerning motor control. Futures studies should analyze this question with a specific focus on these subjects. This result may be related to deficient training programs, placing the athletes at a higher risk of injury instead of focusing on prevention strategies. This conclusion must be supported by other and more specific studies related to training structure in these teams.

Perhaps the most frequently studied risk factor for lateral ankle-ligament sprains is a previous sprain of this complex. This is based on the fact that disruption of a ligament may compromise an important biomechanical stabilizer creating partial deafferentation of the ankle [35]. Our study found statistical significance in the relation between the existence of a primary injury to the ankle and reinjury, as well as with self-perceived instability. The literature is divided about whether or not a previous sprain influences the risk for a future sprain. One of the original prospective risk factor studies is the work of Ekstrand and Gillquist [36] where an increased risk for lateral ankle-ligament injury in athletes who had suffered a prior ankle-ligament sprain was reported. Subsequent studies of soccer and basketball athletes and military recruits undergoing basic training found that they were at increased risk for lateral ankle ligament injury after suffering a prior ankle injury [8] [18] [20] [40] [41]. However, other studies of athletes participating in similar sports have revealed no increased risk for lateral ankle ligament injury after suffering a prior ankle injury [34] [42] [43].

According to our findings after first injury athletes are more predisposed to the repetition of the same injury, and also a significate relation was found between the repetition of the sprain and further sensation of giving away and instability, enhancing the existence of a chain of events towards a chronic ankle instability. In Hertel's new model for instability, the author states that repeated 
episodes of giving way and recurrent ankle sprains are likely to produce further secondary tissue damage, thus resulting in additional pathomechanical impairment [17].

One explanation for the divergent findings may be that the condition of the joint after injury not only depends on the index injury and the associated damage to the ligaments, muscles, and deafferentation of the joint but also on what type of rehabilitation was administered. Whether or not the subject complied with the rehabilitation program, and the quality of recovery that was achieved [35]. Future studies should focus on this point or, at least, include it as an evaluation item.

The natural progression of acute ankle sprains is for subjects to report gradual improvement as the initial symptoms of pain, swelling, and loss of function subside in the weeks after injury [44].

However, lack of compliance with treatment associated with team's pressure to an early return to practice and competition may be responsible for the existence of incomplete rehabilitation [45].

On the other hand, our study confirms the existing theory that reinjury leads to constant feeling of giving away and instability, which some authors consider to be a cycle conducting to injury repetition and chronic instability [34] [43].

There are several limitations that should be considered when interpreting our results. The first and more important is related to the study design. Overall, our results are dependent of the players' retrospective memory, many times referring to periods very distant in their sports career. The main limitation of this study has to do with the use of this type of data being aware of the possible lack of information. More so, our data only offers information concerning self-reported instability, lacking objective measures and assessment. Our study does not include more specific details concerning the first injury (recovery time. severity. mechanism), as well as the number of repetitions, important to establish a cycle of chronic sequelae.

Another limitation of the study is related to omission concerning the type of rehabilitation athletes underwent at the time of the injury. Being this a factor associated with chronic instability, it would be important to have information about the means available in these clubs to fully understand the difference in the health context when compared do major leagues. Also relevant and missing from our data is the type of field for training and playing for these athletes, once is known that, in regional leagues, some fields are equipped with natural turf. while others have artificial turf and some clubs still train and play in fields with no turf. factor that could contribute to the injury rate.

A viable alternative to confirm the results published here would be the development of prospective studies or studies based on official records of the clubs or preferably, the implementation of a permanent scientific observatory for follow-up of the incidence of injuries in the different teams regardless of their status. Inclusion of objective measures (inflammatory signs. pain. and functional 
tests) in this type of database would be important to define associations and relations between different factors. This record would constitute an essential instrument to the training methodological guidance and injury prevention and would also be a valuable source of information to the development of studies like this.

Future studies should be made focussing on different rehabilitation strategies, different resources (human and material) analyzing the role of these factors in the development of chronic ankle instability.

\section{Conclusions}

The discussion about factors that may represent a possible risk factor for injury in sports is as important as the training strategies or results.

Considering ankle injury, despite the lack of other supporting studies, namely in our country, seems urgent the inclusion of strategies to avoid injury repetition, leading to chronic ankle instability. Factors like age, quality in training protocols, position played, limb dominance should be taken into account as factors to consider while preventing chronic ankle instability.

In a moment when prevention is the key to effective clinical work in sports, more individualized clinical/physical work should be planned to answer more specific framing for different athletes.

More studies should be developed to establish definite significant relations between different factors and injuries to prevent the absence of players along with the development of chronic symptoms.

\section{Conflicts of Interest}

The authors declare no conflicts of interest regarding the publication of this paper.

\section{References}

[1] Aoki, H., O’Hata, N., Kohno, T., Morikawa, T. and Seki, J. (2012) A 15-Year Prospective Epidemiological Account of Acute Traumatic Injuries during Official Professional Soccer League Matches in Japan. The American Journal of Sports Medicine, 40, 1006-1014. http://ajs.sagepub.com/lookup/doi/10.1177/0363546512438695 https://doi.org/10.1177/0363546512438695

[2] Dvorak, J. and Junge, A. (2000) Football Injuries and Physical Symptoms. A Review of the Literature. The American Journal of Sports Medicine, 28, S3-S9. https://doi.org/10.1177/28.suppl_5.s-3

[3] Agel, J., Evans, T.A., Dick, R., Putukian, M. and Marshall, S.W. (2007) Descriptive Epidemiology of Collegiate Men's Soccer Injuries: National Collegiate Athletic Association Injury Surveillance System, 1988-1989 through 2002-2003. Journal of Athletic Training, 42, 270-277. http://www.ncbi.nlm.nih.gov/pubmed/17710176

[4] Mallo, J., González, P., Veiga, S. and Navarro, E. (2011) Injury Incidence in a Spanish Sub-Elite Professional Football Team: A Prospective Study during Four Consecutive Seasons. Journal of Sports Science and Medicine, 10, 731-736. 
http://www.ncbi.nlm.nih.gov/pubmed/24149566

[5] Junge, A. and Dvorak, J. (2013) Injury Surveillance in the World Football Tournaments 1998-2012. British Journal of Sports Medicine, 47, 782-788.

http://www.ncbi.nlm.nih.gov/pubmed/23632746

https://doi.org/10.1136/bjsports-2013-092205

[6] Dvorak, J., Junge, A., Derman, W. and Schwellnus, M. (2011) Injuries and Illnesses of Football Players during the 2010 FIFA World Cup. British Journal of Sports Medicine, 45, 626-630. http://www.ncbi.nlm.nih.gov/pubmed/21257668 https://doi.org/10.1136/bjsm.2010.079905

[7] Gribble, P.A., Delahunt, E., Bleakley, C., Caulfield, B., Docherty, C.L., Fourchet, F., et al. (2013) Selection Criteria for Patients with Chronic Ankle Instability in Controlled Research: A Position Statement of the International Ankle Consortium. Journal of Orthopaedic \& Sports Physical Therapy, 43, 585-591.

http://www.ncbi.nlm.nih.gov/pubmed/23902805

https://doi.org/10.2519/jospt.2013.0303

[8] Ekstrand, J. and Tropp, H. (1990) The Incidence of Ankle Sprains in Soccer. Foot \& Ankle International, 11, 41-44.

http://fai.sagepub.com/lookup/doi/10.1177/107110079001100108 https://doi.org/10.1177/107110079001100108

[9] Woods, C. (2003) The Football Association Medical Research Programme: An Audit of Injuries in Professional Football: An Analysis of Ankle Sprains. British Journal of Sports Medicine, 37, 233-238.

http://www.ncbi.nlm.nih.gov/pubmed/12782548 https://doi.org/10.1136/bjsm.37.3.233

[10] Rae, K. and Orchard, J. (2007) The Orchard Sports Injury Classification System (OSICS) Version 10. Clinical Journal of Sport Medicine, 17, 201-204.

https://doi.org/10.1097/JSM.0b013e318059b536

[11] Delahunt, E., Coughlan, G.F., Caulfield, B., Nightingale, E.J., Lin, C.W.C. and Hiller, C.E. (2010) Inclusion Criteria When Investigating Insufficiencies in Chronic Ankle Instability. Medicine \& Science in Sports \& Exercise, 42, 2106-2121. https://doi.org/10.1249/MSS.0b013e3181de7a8a

[12] Ross, S.E. and Guskiewicz, K.M. (2004) Examination of Static and Dynamic Postural Stability in Individuals with Functionally Stable and Unstable Ankles. Clinical Journal of Sport Medicine, 14, 332-338. https://doi.org/10.1097/00042752-200411000-00002

[13] De Vries, J., Kingma, I., Blankevoort, L., van Dijk, C.N. (2010) Difference in Balance Measures between Patients with Chronic Ankle Instability and Patients after an Acute Ankle Inversion Trauma. Knee Surgery Sport, 18, 601-606. http://www.springerlink.com/index/y8368k0805120u66.pdf https://doi.org/10.1007/s00167-010-1097-1

[14] Eils, E. and Rosenbaum, D. (2001) A Multi-Station Proprioceptive Exercise Program in Patients with Ankle Instability/Un Programme d'Exercices Multiples Proprioceptif chez des patients atteints d'instabilite de la cheville. Medicine \& Science in Sports \& Exercise, 33, 1991-1998.

http://articles.sirc.ca/search.cfm?id=S-799457\%5Cnhttp://ezproxy.library.yorku.ca/l ogin

http://search.ebscohost.com/login.aspx?direct=true\&db=sph\&AN=SPHS-799457\&s ite $=$ ehost-live $\% 5 \mathrm{Cn}$

http://www.wwilkins.com https://doi.org/10.1097/00005768-200112000-00003

[15] Palmieri-Smith, R.M., Hopkins, J.T. and Brown, T.N. (2009) Peroneal Activation 
Deficits in Persons with Functional Ankle Instability. The American Journal of Sports Medicine, 37, 982-988. https://doi.org/10.1177/0363546508330147

[16] Van Deun, S., Staes, F.F., Stappaerts, K.H., Janssens, L., Levin, O. and Peers, K.K.H. (2007) Relationship of Chronic Ankle Instability to Muscle Activation Patterns during the Transition from Double-Leg to Single-Leg Stance. The American Journal of Sports Medicine, 35, 274-281. https://doi.org/10.1177/0363546506294470

[17] Hertel, J. and Corbett, R.O. (2019) An Updated Model of Chronic Ankle Instability. Journal of Athletic Training, 54, 572-588. https://doi.org/10.4085/1062-6050-344-18

[18] Milgrom, C., Lavie, O., Shlamkovitch, N., Finestone, A., Eldad, A., Laor, A., et al. (1991) Risk Factors for Lateral Ankle Sprain: A Prospective Study Among Military Recruits. Foot \& Ankle International, 12, 26-30.

http://journals.sagepub.com/doi/10.1177/107110079101200105

https://doi.org/10.1177/107110079101200105

[19] Watson, A.W.S. (1999) Ankle Sprains in Players of the Field-Games Gaelic Football and Hurling. The Journal of Sports Medicine and Physical Fitness, 39, 66-70.

http://www.ncbi.nlm.nih.gov/pubmed/10230172

[20] McKay, G.D., Goldie, P.A., Payne, W.R. and Oakes, B.W. (2001) Ankle Injuries in Basketball: Injury Rate and Risk Factors. British Journal of Sports Medicine, 35, 103-108. https://bjsm.bmj.com/content/35/2/103 https://doi.org/10.1136/bjsm.35.2.103

[21] Valderrabano, V., Barg, A., Paul, J., Pagenstert, G. and Wiewiorski, M. (2014) Foot and Ankle Injuries in Professional Soccer Players. Sports Orthopaedics and Traumatology, 30, 98-105.

https://www.sciencedirect.com/science/article/pii/S0949328X1400060X?via\%3Dihub https://doi.org/10.1016/j.orthtr.2014.04.002

[22] Hawkins, R.D. and Fuller, C.W. (1999) A Prospective Epidemiological Study of Injuries in Four English Professional Football Clubs. British Journal of Sports Medicine, 33, 196-203. http://www.ncbi.nlm.nih.gov/pubmed/10378073 https://doi.org/10.1136/bjsm.33.3.196

[23] Ekstrand, J., Gillquist, J., Möller, M., Oberg, B. and Liljedahl, S.O. (1983) Incidence of Soccer Injuries and Their Relation to Training and Team Success. The American Journal of Sports Medicine, 11, 63-67.

http://www.ncbi.nlm.nih.gov/pubmed/6846683 https://doi.org/10.1177/036354658301100203

[24] Gribble, P.A., Delahunt, E., Bleakley, C., Caulfield, B., Docherty, C., Fourchet, F., et al. (2014) Selection Criteria for Patients with Chronic Ankle Instability in Controlled Research: A Position Statement of the International Ankle Consortium. British Journal of Sports Medicine, 48, 1014-1018. http://www.jospt.org/doi/10.2519/jospt.2013.0303 https://doi.org/10.1136/bjsports-2013-093175

[25] Kaminski, T.W., Perrin, D.H. and Gansneder, B.M. (1999) Eversion Strength Analysis of Uninjured and Functionally Unstable Ankles. Journal of Athletic Training, 34, 239-245. http://www.ncbi.nlm.nih.gov/pubmed/16558571

[26] Akhbari, B., Ebrahimi Takamjani, I., Salavati, M. and Ali Sanjari, M. (2007) A 4-Week Biodex Stability Exercise Program Improved Ankle Musculature Onset, Peak Latency and Balance Measures in Functionally Unstable Ankles. Physical Therapy in Sport, 8, 117-129. https://doi.org/10.1016/j.ptsp.2007.03.004

[27] Ross, S.E. and Guskiewicz, K.M. (2006) Effect of Coordination Training with and without Stochastic Resonance Stimulation on Dynamic Postural Stability of Subjects 
with Functional Ankle Instability and Subjects with Stable Ankles. Clinical Journal of Sport Medicine, 16, 323-328. http://www.ncbi.nlm.nih.gov/pubmed/16858216 https://doi.org/10.1097/00042752-200607000-00007

[28] Cruz-Diaz, D., Lomas-Vega, R., Osuna-Pérez, M.C., Contreras, F.H. and MartínezAmat, A. (2015) Effects of 6 Weeks of Balance Training on Chronic Ankle Instability in Athletes: A Randomized Controlled Trial. International Journal of Sports Medicine, 36, 754-760. http://www.ncbi.nlm.nih.gov/pubmed/25969966 https://doi.org/10.1055/s-0034-1398645

[29] McKeon, P.O., Ingersoll, C.D., Kerrigan, D.C., Saliba, E., Bennett, B.C. and Hertel, J. (2008) Balance Training Improves Function and Postural Control in Those with Chronic Ankle Instability. Medicine \& Science in Sports \& Exercise, 40, 1810-1819. http://www.ncbi.nlm.nih.gov/entrez/query.fcgi?cmd=Retrieve\&db=PubMed\&dopt= Citation\&list_uids $=18799992$ https://doi.org/10.1249/MSS.0b013e31817e0f92

[30] de Noronha, M., Refshauge, K.M., Kilbreath, S.L. and Figueiredo, V.G. (2008) Cross-Cultural Adaptation of the Brazilian-Portuguese Version of the Cumberland Ankle Instability Tool (CAIT). Disability and Rehabilitation, 30, 1959-1965.

http://www.tandfonline.com/doi/full/10.1080/09638280701809872 https://doi.org/10.1080/09638280701809872

[31] Hiller, C.E., Refshauge, K.M., Bundy, A.C., Herbert, R.D. and Kilbreath, S.L. (2006) The Cumberland Ankle Instability Tool: A Report of Validity and Reliability Testing. Archives of Physical Medicine and Rehabilitation, 87, 1235-1241.

https://linkinghub.elsevier.com/retrieve/pii/S0003999306005193 https://doi.org/10.1016/j.apmr.2006.05.022

[32] Kirby, J.L., Houston, M.N., Gabriner, M.L. and Hoch, M.C. (2016) Relationships between Mechanical Joint Stability and Somatosensory Function in Individuals with Chronic Ankle Instability. Foot, 28, 1-6.

http://linkinghub.elsevier.com/retrieve/pii/S0958259216300037 https://doi.org/10.1016/j.foot.2016.04.001

[33] Nielsen, A.B. and Yde, J. (1989) Epidemiology and Traumatology of Injuries in Soccer. The American Journal of Sports Medicine, 17, 803-807. http://journals.sagepub.com/doi/10.1177/036354658901700614 https://doi.org/10.1177/036354658901700614

[34] Hägglund, M., Waldén, M. and Ekstrand, J. (2006) Previous Injury as a Risk Factor for Injury in Elite Football: A Prospective Study over Two Consecutive Seasons. British Journal of Sports Medicine, 40, 767-772.

http://www.ncbi.nlm.nih.gov/pubmed/16855067 https://doi.org/10.1136/bjsm.2006.026609

[35] Beynnon, B.D., Murphy, D.F. and Alosa, D.M. (2002) Predictive Factors for Lateral Ankle Sprains: A Literature Review. Journal of Athletic Training, 37, 376-380.

[36] Ekstrand, J. and Gillquist, J. (1983) Soccer Injuries and Their Mechanisms. Medicine \& Science in Sports \& Exercise, 15, 267. https://insights.ovid.com/pubmed?pmid=6621313 https://doi.org/10.1249/00005768-198315030-00014

[37] Price, R.J. (2004) The Football Association Medical Research Programme: An Audit of Injuries in Academy Youth Football. British Journal of Sports Medicine, 38, 466-471. http://www.ncbi.nlm.nih.gov/pubmed/15273188 https://doi.org/10.1136/bjsm.2003.005165

[38] Hawkins, R.D. (1996) Risk Assessment in Professional Football: An Examination of Accidents and Incidents in the 1994 World Cup Finals. British Journal of Sports 
Medicine, 30, 165-170. http://www.ncbi.nlm.nih.gov/pubmed/8799605 https://doi.org/10.1136/bjsm.30.2.165

[39] Asperti, A.M., Fernandes, T.L., Pedrinelli, A. and Hernandez, A.J. (2017) Sports Injuries among Amateur Athletes at a Brazilian University. Acta Ortopedica Brasileira, 25, 93-98. http://www.ncbi.nlm.nih.gov/pubmed/28642659 https://doi.org/10.1590/1413-785220172502165651

[40] Surve, I., Schwellnus, M.P., Noakes, T. and Lombard, C. (1994) A Fivefold Reduction in the Incidence of Recurrent Ankle Sprains in Soccer Players Using the Sport-Stirrup Orthosis. The American Journal of Sports Medicine, 22, 601-606. http://journals.sagepub.com/doi/10.1177/036354659402200506 https://doi.org/10.1177/036354659402200506

[41] Tropp, H., Askling, C. and Gillquist, J. (1985) Prevention of Ankle Sprains. The American Journal of Sports Medicine, 13, 259-262.

http://journals.sagepub.com/doi/10.1177/036354658501300408 https://doi.org/10.1177/036354658501300408

[42] Baumhauer, J.F., Alosa, D.M., Renström, P.A.F.H., Trevino, S. and Beynnon, B. (1995) A Prospective Study of Ankle Injury Risk Factors. The American Journal of Sports Medicine, 23, 564-570.

http://journals.sagepub.com/doi/10.1177/036354659502300508 https://doi.org/10.1177/036354659502300508

[43] Tropp, H., Ekstrand, J. and Gillquist, J. (1984) Stabilometry in Functional Instability of the Ankle and Its Value in Predicting Injury. Medicine \& Science in Sports \& Exercise, 16, 64-66. https://insights.ovid.com/pubmed?pmid=6708781 https://doi.org/10.1249/00005768-198401000-00013

[44] Hertel, J. (2002) Functional Anatomy, Pathomechanics, and Pathophysiology of Lateral Ankle Instability. Journal of Athletic Training, 37, 364-375. http://www.ncbi.nlm.nih.gov/pubmed/12937557

[45] Alexandre, D., De Almeida, R.E., Dutra, T., Silva, D.O. and De Lima, E.V. (2003) Incidência de lesões no futebol profissional do brasil. Revista Digital Buenos Aires, 9, 1060-1063. 


\section{Appendix}

Socio-demographic and anthropometric questionnaire

Age (Years) __ Weight (kg) Height $(\mathrm{cm})$

Average weekly training time

Field position

Football practice years

The following questionnaire aims to define whether to be integrated into the group "with functional ankle instability" or in the group "without functional ankle instability".

Please read the questions carefully and tick visibly.

\begin{tabular}{|l|c|c|}
\hline & Left & Right \\
\hline What is your dominant member (the one with which you shoot a ball)? & $\square$ & $\square$ \\
\hline
\end{tabular}

\begin{tabular}{|l|c|c|}
\hline & Yes & No \\
\hline $\begin{array}{l}\text { Have you ever had a sprained ankle being unable to put weight on your } \\
\text { foot, or having to resort to crutches? }\end{array}$ & $\square$ & $\square$ \\
\hline
\end{tabular}

If you answered YES, please proceed to the next question. If you answered NO, your questionnaire ends here. Thanks.

\begin{tabular}{|l|c|c|}
\hline & Yes & No \\
\hline After the first sprain, did you repeat the injury one or more times? & $\square$ & $\square$ \\
\hline $\begin{array}{l}\text { Do you feel that your ankle is unstable or sometimes gives you the feeling of } \\
\text { failing or giving away? }\end{array}$ & $\square$ & $\square$ \\
\hline
\end{tabular}

If you answered NO to both of the previous questions, your questionnaire ends here. Thanks.

If you answered YES to any of the previous questions, please answer the next set of questions by selecting for each question ONLY ONE point that BEST describes your ankle.

\begin{tabular}{|l|c|c|c|}
\hline & Left & Right & Score \\
\hline 1- I have pain in my ankle & & & \\
Never & $\square$ & $\square$ & 5 \\
During Sport & $\square$ & $\square$ & 4 \\
Running on uneven surfaces & $\square$ & $\square$ & 3 \\
Running on level surfaces & $\square$ & $\square$ & 2 \\
Walking on uneven surfaces & $\square$ & $\square$ & 1 \\
Walking on uneven surfaces & $\square$ & $\square$ & 0 \\
\hline 2- My ankle feels UNSTABLE & & & \\
Never & $\square$ & $\square$ & 4 \\
Sometimes during sport (not every time) & $\square$ & $\square$ & 3 \\
Frequently during sport (every time) & $\square$ & $\square$ & 2 \\
Sometimes during daily activity & $\square$ & $\square$ & 1 \\
Frequently during daily activity & $\square$ & $\square$ & 0 \\
\hline
\end{tabular}




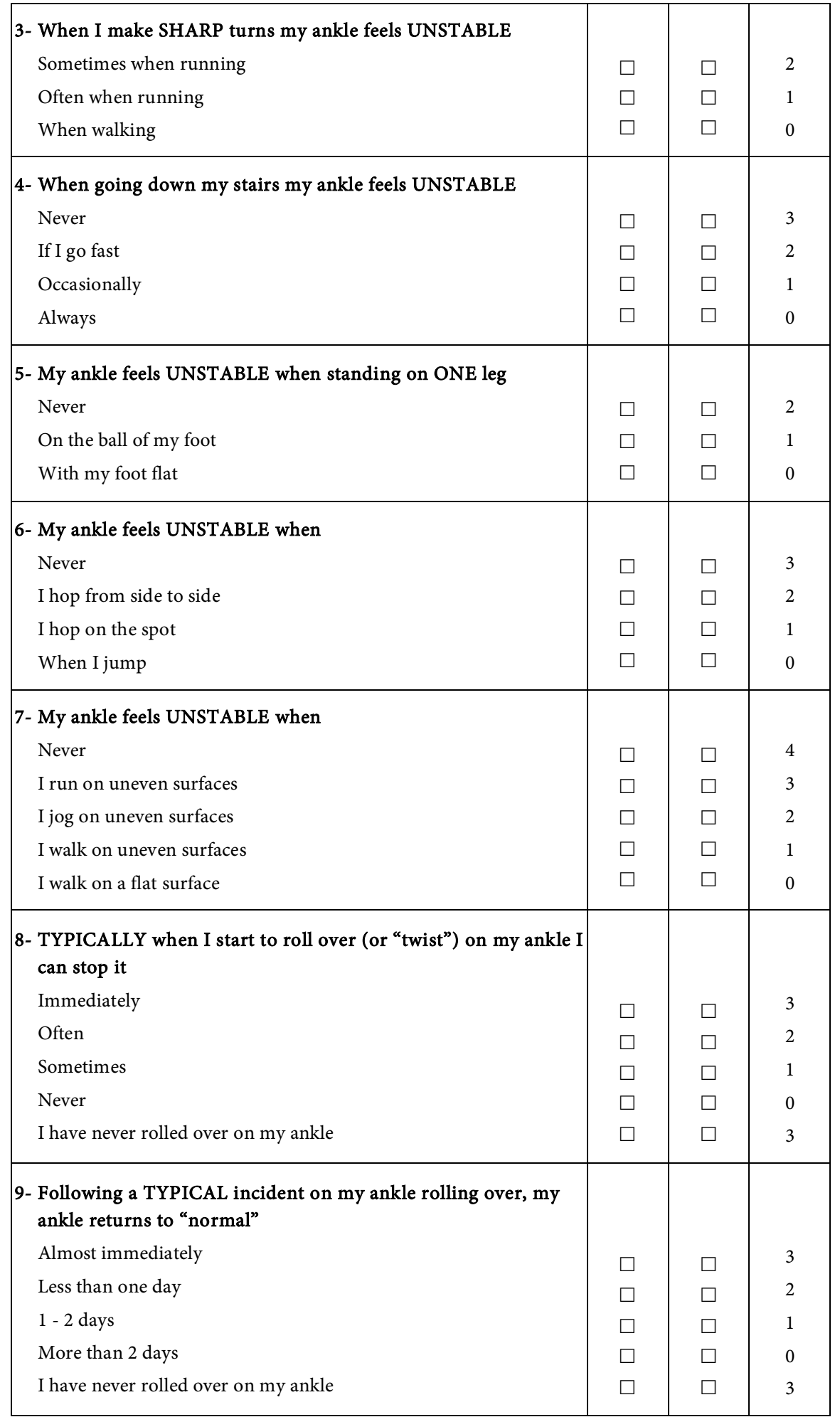

